\title{
Redes sociales, docencia universitaria y escultura barroca española. Reflexiones y posibilidades desde el contexto de la innovación
}

\author{
Juan Antonio SÁNCHEz LóPEZ \\ Universidad de Málaga \\ jasanchez@uma.es \\ Antonio Rafael Fernández PARADAS \\ Universidad Internacional de Andalucía \\ antonioparadas@hotmail.com
}

\section{Resumen}

Las redes sociales revelan inmejorables potencialidades en el contexto de la innovación educativa. Por esta causa, pueden ser una herramienta muy eficaz para el conocimiento de temáticas tan específicas como la escultura barroca española.

Palabras clave: escultura barroca; redes sociales; educación; universidad

\section{Social networks, University Teaching and Spanish Baroque Sculpture. Reflec- tions and possibilities from educational innovation}

\begin{abstract}
Social networks are emerging from educational innovation context as potential resources. For this reason Social networking can be a powerful tool for knowledge of specific university subjects such as Spanish Baroque Sculpture.
\end{abstract}

Key Words: Baroque sculpture; social networks; education; university

Referencia normalizada:

Sánchez López, J. A. y Fernández Paradas, A. R. (2013) Redes sociales, docencia universitaria y escultura barroca española. Reflexiones y posibilidades desde el contexto de la innovación. Historia y Comunicación Social. Vol. 18. Nº Especial Noviembre. Págs. 713-723.

Sumario: 1. Introducción. 2. La escultura barroca y los procesos de enseñanza-aprendizaje. 3. Canales alternativos del conocimiento. Redes sociales y escultura. 4. La escultura barroca en las redes sociales. Posibilidades de aprendizaje cooperativo. 5. Conclusiones. 6. Referencias bibliográficas. 


\section{Introducción}

A nadie escapa cómo las redes sociales han revolucionado las formas y modos de pensar, las conductas y hasta la vida cotidiana de las sociedades modernas, más allá de idiosincrasias, nacionalismos y culturas (Pantoja, 2011: 218-226). En el contexto de la innovación docente, la inquietud por ensayar, experimentar, gestionar y proponer estrategias para la construcción del conocimiento hace casi 'obligado' el recurso a las nuevas tecnologías, en pro de nuevos hábitos de difusión y comprensión del mismo de manera cooperativa, sociabilizando pautas conductuales para alentar, a su vez, nuevos hábitos de transmisión y generación de contenidos, con la mirada puesta más que nunca, en los usuarios/protagonistas de la educación.

En este punto, el blog y otras 'formas' de las redes sociales aparecen como recursos excepcionales y susceptibles de rentabilizar a pleno rendimiento las potencialidades de determinados campos del conocimiento en el plano de la innovación educativa. Uno de ellos sería la escultura barroca española. A nuestro entender, nos situamos frente a una materia que amplifica, como pocas, esta realidad, abriéndola hacia perspectivas culturales de globalización y dinamización, al tiempo que se optimizan y canalizan vías alternativas de acceso a la información y formación con perspectivas pedagógicas, investigadoras, educativas y docentes alto grado de optimización. Teniendo en cuenta lo expuesto, las redes sociales ostentan un protagonismo inequívocamente 'existencial' en cualquiera de las fases de este proceso.

La cultura digital y las redes sociales saltan a nuestro encuentro de manera súbita e inmediata, cuestionando la 'pasividad' del usuario. Desde el ámbito más práctico, se erigen en un auténtico repositorio de información, altamente estimulante de cara a ir desarrollando los hábitos adecuados para adquirir/trasmitir/acceder a un conocimiento espontáneo, cooperativo e 'imprevisible'. En este punto, el generador de contenidos aparece como el agente controlador y filtrante de semejante bagaje.

\section{La escultura barroca y los procesos de enseñanza-aprendizaje}

A lo largo de la Historia del Arte, pocas manifestaciones como la escultura barroca son capaces de aunar la esencia de la obra de arte como instrumento que visualiza/ materializa un mensaje-lenguaje a través de la visualización de un componente externo que denominamos "forma" y en cuya complejidad quedan integrados no sólo unos contenidos 'traducidos' con unos determinados valores estéticos, sino un artista que, mediante un acto de creación, hace valer su deseo de comunicación ante la sociedad.

"Abrir a los jóvenes el mundo del aprendizaje" (Postman, 1999), debe ser uno de los indicadores de éxito de todo proceso educativo, en cuyo desarrollo el docente arbitra las claves de las estrategias y estímulos necesarios para superar todo lastre que pueda bloquearlo, obstaculizarlo, inutilizarlo, en definitiva. En este punto, cuando las 
iniciativas de innovación se muestran rotunda y literalmente 'funcionales' surge un auténtico entusiasmo cuando, según Ramos (2002: 27-47), "los temas y las actividades conectan con los intereses y motivaciones intrínsecas del alumnado". En otras palabras, se trataría de promover una selección y priorización del saber basada en el aprendizaje de contenidos culturales relevantes y desde una profunda sensibilización/ implicación del docente con el contexto socio-cultural y antropológico específico del alumnado.

Para Carbonell (2002: 21), la tesitura no admite dudas, habida cuenta de que una de las vías para impedir el referido bloqueo pasa por hacer realidad una intensa identificación entre lo que el docente enseña y el alumnado aprende y, para lograrlo con rotundidad, no hay más camino que focalizar, seleccionar y disponer inteligentemente "la enseñanza y el aprendizaje de contenidos culturalmente relevantes, socialmente útiles y psicológicamente adaptados a los intereses y necesidades del alumnado". Efectivamente es justo y necesario, seleccionar y priorizar los saberes más formativos y, a ser posible, incardinados y adaptados a las necesidades del entorno en el que han nacido, crecido y viven los alumnos, pero invocando, al tiempo, "la deseable eficiencia de un proceso investigativo canalizado a costa de una permanente indagación, confrontación y experimentación" (Ramos, 2002: 35).

En este sentido, todos somos conscientes de lo tremendamente equivocado de determinados planteamientos que continúan propiciando la falta de estimación/valoración/consideración hacia lo que el mismo Ramos (2002: 37) denomina como "las ideas previas y la cultura cotidiana del alumnado"; ante lo cual el problema sólo tiene un nombre: la ausencia de motivación. La Historia del Arte está llamada a desempeñar un rol decisivo en estas lides, pues por su propia naturaleza de disciplina ocupada del estudio de las creaciones visuales puede/debe optimizar su liderazgo en el terreno de la innovación, a la hora de rentabilizar las tremendas potencialidades de trabajar con imágenes mediante estrategias ad hoc pertinentemente ideadas, diseñadas y proyectadas hacia sus destinatarios (López, 2013: 118-119), ejercicios en red y el diseño de actividades que postulen por métodos académicamente contrastados (Lozano, 2004).

La investigación en innovación educativa permite descubrir al alumnado vías y técnicas procesuales para abordar tareas de indagación, reflexión y experimentación, diversificando los espacios y lugares educativos e incrementando su autonomía al dotarlo de la capacidad de búsqueda y experimentación reflexiva a partir de lo que ve, percibe y, en última instancia, vive (Ramos, 2002: 35). La distinción entre "cultura de élite" y "cultura popular" -que lleva pareja la establecida entre masscult ("cultura de masas") y folklore ("cultura popular")- contribuye a proporcionar canales hermenéuticos de aproximación y comprensión de este fenómeno que, dicho sea de paso, constituye asimismo un auténtico 'reto', en términos de innovación.

La escultura barroca se erige, pues, en esta tesitura como una materia de innegable interés experimental para conciliar las pautas de la docencia universitaria, con las propuestas de innovación educativa y la complicidad de las redes sociales y la necesidad de optimizar el trabajo con imágenes, ya tenido en cuenta desde otras materias 
del campo de las Ciencias Sociales (Arroyo, 2013: 211-213); máxime cuando figura como contenido relevante en materias troncales, obligatorias y optativas de los planes de estudio universitarios españoles e, incluso, goza de un reconocimiento y puesta en valor a nivel externo a través de eventos de innegable impacto internacional (Bray, 1999). Es más, pensamos que adoptar la escultura barroca española como uno de los puntos de partida para propuestas de innovación educativa y docente universitaria en materia de Historia del Arte supone una oportunidad excepcional para rentabilizar al máximo las posibilidades de las redes sociales, para desde ellas, con ellas y gracias a ellas ofrecer al alumnado un campo estimulante para aprender y conocer más y mejor de nuestra propia Historia, de nuestro entorno y sociedad y contribuyendo a la puesta en valor de los valores patrimoniales y culturales.

En la sociedad de la Información, las Nuevas Tecnologías de la Información y la Comunicación (NTIC's) han generado nuevas formas de asociación e interrelación colectiva desde su pasmosa irrupción en las últimas décadas del siglo XX. La web 2.0 ha abierto las posibilidades de Internet. Para ser más exactos, "el entorno de aprendizaje electrónico reúne características que son especialmente poderosas para la colaboración, tales como su: interactividad, ubicuidad, y sincronismo" (Zañartu, 2007: 1-9) y es aquí donde tanto el e-learning como otros 'modos' de aprendizaje colaborativo encuentran terreno abonado para su expansión sin fronteras. En las páginas siguientes, abundaremos en el impacto y proyección de las redes sociales, o web 2.0 (Facebook, Twitter...), como nivel de contacto permanente con y entre los grupos de trabajo en el aula, amén de herramienta interesante a efectos de motivación y estímulo de la curiosidad intelectual y del aprendizaje.

\section{Canales alternativos del conocimiento. Redes sociales y escultura}

Quizás sea la Historia del Arte una de las áreas de conocimiento donde los procesos de innovación educativa hayan venido adoleciendo de cierta 'lentitud'. Lentitud a la hora de reaccionar ante las nuevas perspectivas, lentitud en cuanto a las vías para difundir, propagar y publicar los resultados de la investigación y lentitud también en hacer suyos y recepcionar con entusiasmo los retos de la innovación. A propósito de la cuestión, González Tirados (1999: 93) ha sido contundente al sentenciar que "La verdadera dificultad de la innovación y el cambio en la enseñanza universitaria se encuentra en el cambio de actitudes del profesorado frente a las nuevas tecnologías". Por supuesto que, dentro de todo este proceso, la referida lentitud se ha visto reflejada asimismo en la asimilación de nuevos soportes de edición de contenidos, y, en última instancia, y por supuesto, en el modus operandi que posibilita al docente interactuar con el alumno en el proceso educativo, dada la convergencia de múltiples aspectos cognitivos y socio-afectivos. En nuestro caso, el uso de las redes sociales favorece que el alumnado ejerza un control efectivo y, a la par, distendido sobre su propio aprendizaje (Martín, 2004: 55-70), al tiempo que le brinda la posibilidad de desarrollar el pensamiento crítico, sin dejar de respetar su autonomía (Fëdorov, 2005: 1-10). 
Existen términos como "Historia del Arte" abrumadoramente infinitos. La experiencia de teclearlo en Internet puede suponer enfrentarnos a un número de registros tan inmenso como disperso, habida cuenta de las diferencias cualitativas que, simplemente, nos sitúan ante una perspectiva informativa para la cual no cabe más que una realidad: saturación. Sin embargo, si los blogs y las redes sociales dejan a un lado su rol habitual como repositorios y asumen plenamente su condición de medios en los que se puede generar un conocimiento cooperativo, es entonces cuando demuestran tener un provechoso futuro al servicio de la enseñanza y, en nuestro caso, de la escultura barroca española.

Como toda obra de arte, la escultura es un testimonio documental en toda regla y un interesante foco emisor de conocimiento histórico-artístico, si se le somete a un interrogatorio bien planteado. De hecho, y como obra de arte esencialmente considerada, la escultura es ya per se un agente generador del conocimiento a través de un elenco de campos informativos tan diferentes como la dimensión social del escultor, el contexto histórico, la iconografía, el estilo, la policromía, las técnicas, etc. Por otro lado, desde su interacción con las fuentes literarias y los documentos de archivo se extraen referencias taxativas respecto a cuestiones de autoría, datación, comitente, condiciones, ubicación, función etc.

Sin embargo, el uso de las redes sociales, Facebook (Plaza, 2013: 257-258), por ejemplo, nos sitúan ante un mundo tan fascinante como insospechado no sólo a la hora de amplificar conocimientos, sino desde la misma capacidad de generar conocimientos de manera cooperativa y a partir de obras descontextualizadas entre los miembros de la comunidad, lo cual también supone de paso una transformación y evolución sustanciales en las formas de edición de contenidos frente a los medios tradicionales para hacerlo. Es más, podría hablarse de todo un proceso de retroalimentación en virtud del cual el conocimiento corporativo generado en una red social, un blog, un foro, o una lista de distribución retorna a los canales tradicionales de edición, en papel o exclusivamente online. Como veremos, para la escultura barroca, la base del trabajo suele ser una pieza dispersa y desconocida. Su 'aparición' o, si se prefiere su 'presencia' en las redes sociales convierte de inmediato a la "aldea global" en un meeting point desde el que surgen impresiones, comentarios, discusiones y reflexiones. A la postre, el debate sirve de estímulo para la discusión y ulterior difusión en forma de publicaciones científicas, desde el instante en el que ese conocimiento es convenientemente aprehendido, diseccionado y sintetizado por uno o varios usuarios especializados.

Llegados a este punto, podríamos preguntarnos ¿cómo sucede todo esto? ¿Cuál es el origen, desarrollo y presunto objetivo del proceso aplicado a la escultura barroca, motivo de nuestro estudio? Pues todo surgiría, y no han sido una, ni dos, sino cientos de veces...a partir del momento en el que, desplazando el papel inicialmente desempeñado por un documento escrito u otra fuente, a "alguien" se le ocurre subir y colgar en una red social el testimonio fotográfico de una escultura que, por las vías más variopintas, ha captado su atención. Esa fotografía es, por naturaleza y por circunstancias, una imagen descontextualizada, susceptible de abrir insólitas posibi- 
lidades al poderse convertir y, de hecho, haberse convertido en la base de una nueva investigación, ya sea por ella misma o por los comentarios, observaciones, preguntas que inspira. Por supuesto que no olvidamos la mirada inquieta del investigador que proyecta su intelecto en la escultura que, en algún momento indeterminado y en múltiples circunstancias, pudo encontrarse -y con frecuencia por pura 'casualidad'en una red social.

En este sentido, si el estudioso rentabiliza el proceso de cara a ampliar el catálogo de obras de un artista, apostillar sus relaciones con otras obras y focos creativos y escudriñar con seguridad la dimensión social del mismo, también las redes sociales propician la interconexión entre el docente y el alumnado, al revelarse como una herramienta idónea para motivar, estimular, entusiasmar, implicar y enseñar a los jóvenes que, como hijos de su tiempo, han nacido y crecido con ellas y, hoy por hoy, y precisamente por ello, vienen a ser los máximos especialistas en su manejo.

\section{La escultura barroca en las redes sociales. Posibilidades de aprendizaje cooperativo}

Imaginemos que un "amigo" (término aplicado en la consideración que Facebook hace del mismo) nos 'descubre' una escultura que, por distintas circunstancias, soluciona muchas de nuestras incertidumbres en investigaciones en curso o postergadas por distintas circunstancias. ¿De qué manera nos soluciona este 'acontecimiento' el planteamiento de la investigación? En principio, podrían ocurrírsenos distintas formas.

Una podría ser la de 'suministro'. Los usuarios pueden acceder y conocer obras anónimas y confrontarlas con las documentadas en un determinado contexto. La pieza difundida a través de las redes sociales permite realizar y verificar análisis comparativos entre unas y otras. La comparación estilística nos permite formular, merced a las analogías formales y técnicas detectadas, una propuesta de atribución en la que resulta decisiva la obra localizada en la red social, en términos de responsabilidad y presencia sin olvidar el peso específico que el aparato crítico detenta, por derecho propio, en el proceso.

Nuestra propia experiencia así nos lo demuestra. Gracias a una fotografía compartida en Facebook, de una escultura documentada del escultor antequerano del siglo XVIII Diego Márquez y Vega, pudimos atribuir al mismo el Crucificado de la Misericordia de San Pedro de Antequera, además de establecer una propuesta de periodización para su obra (Fernández, 2013: 123-152).

De la misma manera, esta misma obra 'desconocida' que un día nos apareció en Facebook repercute positivamente en relación a la procedencia, y podríamos buscar algunos motivos. Por ejemplo, para ampliar el catálogo de obras de un artista y superar las limitaciones de las vías tradicionales de gestación del conocimiento, que 
hubieran impedido localizar y relacionar con el mismo obras documentadas, pero dispersas por un espectro geográfico tan amplio como imprevisible.

Llegados a este punto, se impone aquí otra realidad evidente como es la habilidad, la facilidad, diríase incluso la virtud que las redes sociales e Internet poseen y de la que hacen gala de cara a materializar su principal cometido: acortar distancias y acercar personas. En esta tesitura, las redes sociales aplicadas a la escultura barroca demuestran cómo, aparte de la mera puesta en valor o el hecho de 'descubrir' obras, la infinita difusión topológica de las redes sociales han hecho visibles obras en localizaciones insólitas, poniendo de manifiesto que los caminos del comercio del arte eran, en su momento, muchos más amplios de los que hoy se pueda tener constancia, sin infravalorar tampoco las infinitas posibilidades que el devenir de una escultura/ obra de arte puede experimentar a lo largo de su historia material, ya sea a través de sus 'migraciones' (expolio, dote de boda, obsequio,...) o de situaciones particulares relacionadas con el encargo, la propia visión del mundo que rodeaba al escultor por medio de su obra o las circunstancias del comitente y/o propietario.

Un ejemplo significativo de ello puede ser el de una Virgen Dolorosa de la familia de escultores malagueños Asensio de la Cerda existente en la iglesia de la Barca de San Pablo, en La Valleta, capital de Malta. La obra fue dada a conocer desde Facebook por dos jóvenes sevillanos que, conocedores de los estudios sobre estos artistas del XVIII, se vieron literalmente sorprendidos durante sus vacaciones en la isla cuando visitando una iglesia se 'toparon' literalmente con una obra que, sin duda, no había sido creada en ese contexto geográfico e invitaba a preguntarse a quien pudiese identificarse de qué modo peregrino podía haber llegado hasta allí. Y, dicho y hecho, sus 'descubridores' no tardaron en invitar a la comunidad virtual a compartirla como 'curiosidad', algo 'pintoresco' y aún como 'sorpresa', al localizar esta obra en paradero tan "exótico" con respecto a su lejana procedencia en tierras malagueñas (Sánchez, 2005: 283-316).

En estrecha relación con lo anterior, tendríamos la capacidad de las redes sociales de publicar imágenes conservadas en espacios privados, $\mathrm{y}$, consecuentemente, de difícil acceso. Sin esa imagen compartida, sería muy difícil, por no decir imposible, tener conocimiento de su existencia.

Son muchas, como vemos, las opciones que, como vemos, nos ofrece esa escultura que un día apareciera en una red social; obra descontextualizada para nosotros, y contextualizada para el internauta que la subió a la misma. Y esas posibilidades se amplían hasta límites desconocidos para el investigador, para el aficionado o para el usuario, no digamos nada para el alumnado universitario desde el punto de vista tanto del aprendizaje y de la innovación docente y educativa. Independientemente de que vertamos la mirada docente o la investigadora, es indudable que estas situaciones siempre aportan nuevas perspectivas de investigación y sugieren nuevas perspectivas que vienen a ampliar el universo barroco por cuanto la escultura ocupa un lugar inmaterial en la red social. 
Entre ellas también se cuenta el desarrollo del debate crítico al que se presta la imagen, por lo demás favorecido a través de sus plataformas por redes sociales como Facebook, Tuenti o Linkedin. De hecho, la disponibilidad que una red social suele brindar en relación a una foto/imagen suele oscilar entre varias alternativas: el libre acceso dentro de los límites de una comunidad, la imagen subida a un grupo cerrado o abierto, o la especialización que informe a los mismos componentes del grupo en su condición de especialistas en escultura barroca en nuestro caso.

Como ejemplo demostrativo traemos a colación el significativo caso del Cristo de la Columna de José María Ruiz Montes. La foto de esta obra contemporánea fue compartida en la página de Facebook del I Máster Propio de Escultura Barroca Española: desde los Siglos de Oro a la Sociedad de la Información y las Redes Sociales (https://www.facebook.com/masteresculturabarroca) dirigido por los autores de este trabajo. Concretamente, fueron 36.431 las personas que vieron dicha imagen fotográfica. Al dato del número de personas que vieron la imagen, tenemos que añadir los 835 "Me gusta" y los 130 comentarios recibidos por la misma, con lo cual llegaríamos a las 37.396. En la misma página, los directores del proyecto también compartimos una imagen con un texto en el que se podía leer: "Yo también pienso que la imaginería del siglo XXI es arte contemporáneo". Teniendo en cuenta lo intensamente 'polémicos' y controvertidos que suelen ser los debates de este tipo, podemos decir que el resultado, a nivel de respuesta, fue sencillamente fascinante.

Para nosotros, y además de la mera faceta divulgativa/informativa/publicitaria, el uso 'interesado' de esta imagen -que llamamos el "Cristo de los 30.000 amigos en Facebook"-, y visto a título de propuesta/ejemplo/caso práctico, nos brindó la posibilidad de experimentar y jugar con las posibilidades de las redes sociales en su aplicación al conocimiento y, por extensión, investigación, docencia y proyección al ámbito educativo de la escultura barroca. El 'experimento' fue un éxito al conllevar una oleada de comentarios que favorecieron la puesta en valor de la escultura, de modo versátil y 'poliédrico', habida cuenta de que abarcaban desde lo anatómico, artístico, devocional, técnico, etc.. Sin duda, estas cifras convierten a esta obra del arte de la imaginería en un caso paradigmático del 'poder' efectivo, incuestionable $\mathrm{y}$ real que tienen las redes sociales en la difusión de contenidos y nos hizo pensar, y mucho, en sus inmensas posibilidades en el marco de la docencia universitaria.

\section{Conclusiones}

En función de lo expuesto en las páginas precedentes y de lo reflexionado en este último apartado, pensamos que propuestas experimentales como esta última y la apuesta por el valor instrumental de las redes sociales pueden ser una buena manera para aplicar nuevas prácticas y estrategias docentes, favoreciendo la adquisición de conocimientos por parte del alumnado gracias a las redes sociales. No podemos olvidar que los alumnos de Historia del Arte, en su condición de "nativos digitales", están 
profundamente familiarizados con las redes sociales desde su más temprana edad, y, por este motivo y más que nunca, a los docentes se nos "requiere transformar el aula en una comunidad de investigación abierta, flexible, rica en estímulos y participativa que integra, acepta y promueve la comunicación, el debate, la confrontación, la indagación, la experimentación y la verificación de las hipótesis, teorías e ideas" (Ramos, 2002: 45-46). De ahí lo interesante de estas experiencias a la hora de hacer conseguir esa"preparación real de los alumnos para el ejercicio de las futuras actividades profesionales" señalada por González Tirados (1999: 95) como uno de los objetivos de la innovación educativa. Está claro que el alumnado tiene ante sí la posibilidad de trabajar no solamente el desarrollo de análisis críticos con respecto a la escultura, sino en competencias relacionadas con el uso y manejo de las redes sociales desde un punto de vista profesional en sentido estricto. Los modos de hacerlo le pueden hacer partir de tales recursos para realizar un análisis artístico de la obra, atendiendo a los puntos referidos anteriormente y/o la consideración de dichos conceptos a la hora de crear una ficha de catalogación de la pieza o realizar un ensayo sobre la importancia de esta obra dentro de la imaginería del siglo XXI, si por ejemplo se hubiese elegido nuestro "Cristo de los 30.000 amigos en Facebook".

\section{Referencias bibliográficas}

ARROYO VÁZQUEZ, M. L.; SAGREDO SANTOS, A.; RÁBANO LLAMAS, M. (2013). "La historia estadounidense a través del arte: su análisis y recepción en el entorno virtual universitario español". En SANTAMARÍA LANCHO, M. y SÁNCHEZ-ELVIRA PANIAGUA, A. (coords.) (2013). Innovación Docente Universitaria en Entornos de Aprendizaje Enriquecidos. Madrid: UNED. Madrid. p. 211-213.

BRAY, X. (1999). The Sacred Made Real. Spanish Painting and Sculpture 16001700. London: National Gallery of Art-Yale University Press.

CARBONELL SEBARROJA, J. (2002). "El profesorado y la innovación educativa". En CAÑAL DE LEÓN, P. (coord.) (2002): La Innovación Educativa. Madrid: Akal-UNIA. p. 21.

FËDOROV, A. N. (2005). "Siglo XXI, la Universidad, el Pensamiento Crítico y el Foro Virtual". En: Revista Digital UMBRAL 2000: por una educación para un mundo nuevo, $\mathrm{n}^{\circ} 17$, Santiago de Chile: REDUC, $10 \mathrm{p}$.

FERNÁNDEZ PARADAS, A. R. (2013). "El hijo prodigo de una paternidad deseada. Diego Márquez y Vega y el Crucificado de la Misericordia de la Parroquia de San Pedro de Antequera". En: Revista de Estudios Antequeranos, $\mathrm{n}^{\circ}$ 16, Antequera: Unicaja, p. 123-152.

GONZÁLEZ TIRADOS, R. M. (1999). "La innovación educativa en las universidades". En: Aula abierta, no 73, Oviedo: Universidad, p. 93-102.

LÓPEZ DÍAZ, J. y VIGARA ZAFRA, J. A. (2013). "Incorporación de herramientas interactivas y cooperativas para la difusión de los conocimientos y sinergias en los procesos de aprendizaje de asignaturas artísticas en entornos virtuales". En 
SANTAMARÍA LANCHO, M. y SÁNCHEZ-ELVIRA PANIAGUA, A. (coords.) (2013). Innovación Docente Universitaria en Entornos de Aprendizaje Enriquecidos. Madrid: UNED. Madrid. p. 118-119.

LOZANO DÍAZ, A. (2004). "Comunidades de aprendizaje en red: diseño de un proyecto de entorno colaborativo". En: Teoría de la Educación, n ${ }^{\circ}$ 5, Salamanca: Universidad, $7 \mathrm{p}$.

MARTÍN-MORENO CERRILLO, Q. (2004). "Aprendizaje colaborativo y redes de conocimiento". En Actas de las IX Jornadas Andaluzas de Organización y Dirección de Instituciones Educativas. Granada, 15-17 de diciembre de 2004. Granada: Grupo Editorial Universitario. p. 55-70.

PANTOJA CHAVES, A. (2011). "Los nuevos medios de comunicación social: las redes sociales". En: Tejuelo, $\mathrm{n}^{\circ}$ 12, Murcia: ANABAD, p. 218-226.

PLAZA, V.; PLAZA, C.; CALVENTE, D. (2013). "El uso de las redes sociales en la educación superior: una experiencia piloto". En SANTAMARÍA LANCHO, M. y SÁNCHEZ-ELVIRA PANIAGUA, A. (coords.) (2013). Innovación Docente Universitaria en Entornos de Aprendizaje Enriquecidos. Madrid: UNED. Madrid. p. 257-258.

POSTMAN, N. (1999). El fin de la educación. Barcelona: Octaedro.

RAMOS GARCÍA, J. (2002). "Motivación, entorno e investigación". En CAÑAL DE LEÓN, P. (coord.) (2002): La Innovación Educativa. Madrid: Akal-UNIA. p. $27-47$.

SÁNCHEZ LÓPEZ, J. A. y RAMÍREZ GONZÁLEZ, S. (2005-2006). "Proyección social, endogamia y continuismo artístico. Los Asensio de la Cerda, una familia de escultores en la Málaga Ilustrada". En: Boletín de Arte, n 26-27, Málaga: Universidad, p. 283-316.

ZAÑARTU CORREA, L. M. (2007). "Aprendizaje colaborativo: una nueva forma de Diálogo Interpersonal y en Red". En: Contexto Educativo, Revista Digital de Educación y Nuevas Tecnologías, $\mathrm{n}^{\circ}$ 28, Nueva Alejandría (Argentina), 9 p.

\section{Los autores}

Juan Antonio Sánchez López es Doctor en Historia del Arte y Profesor Titular del Departamento de Historia del Arte de la Universidad de Málaga. En su trayectoria profesional desarrolla progresiva y/o simultáneamente cuatro vías de investigación: Historia y temas del Arte de la Edad Moderna, Iconografía, Historia de la Escultura y Creación Mediática y Arte Contemporáneo. Desde 1999 se suma una quinta, orientada hacia la cuestión de los Estudios de Género, Historia e Historia del Arte. Todas ellas se ven oportunamente reflejadas y consolidadas en sus publicaciones y docencia cotidiana en los diferentes ciclos formativos, dirección de Tesis Doctorales, Memorias de Licenciatura, Trabajos fin de Máster y Trabajos tutelados DEA, participación en proyectos, cursos, seminarios y congresos y demás acciones de difusión 
de los resultados científicos, a nivel nacional e internacional. Actualmente es director y docente del Máster de Escultura Barroca Española, impartido en la Universidad Internacional de Andalucía e investigador principal del Proyecto de Innovación Educativa (PIE 13-102) de la UMA.

Antonio Rafael Fernández Paradas es Doctor en Historia del Arte, Licenciado en Documentación y Perito Tasador en Antigüedades y Obras de Arte. Actualmente, forma parte del claustro de profesores de la Universidad Internacional de Andalucía. Ha trabajado en diversas casas de subastas de arte (Durán y Lamas Bolaño). Especialista en Artes Decorativas, sus líneas de investigación versan sobre iconografía religiosa, el círculo de escultores antequeranos, historia e historiografía del mueble español, así como cerámica, marfiles y cuestiones relacionadas con el mercado del arte. Actualmente es director y docente del Máster de Escultura Barroca Española, impartido en la Universidad Internacional de Andalucía e investigador colaborador del Proyecto de Innovación Educativa (PIE 13-102) de la UMA. 